\title{
Analisis Sistem Pelaksanaan Kelas Ibu Hamil di Puskesmas Malalak dan Biaro Kabupaten Agam
}

\author{
Ayu Nurdiyan ${ }^{1}$, Desmiwarti ${ }^{2}$, Rizanda Machmud ${ }^{3}$
}

\begin{abstract}
Abstrak
Kelas ibu hamil merupakan sarana belajar bersama bagi ibu hamil agar memperoleh pengetahuan yang cukup untuk mencegah komplikasi, meningkatkan cakupan kunjungan ibu hamil dan melakukan persalinan pada tenaga kesehatan. Tujuan penelitian ini adalah untuk menganalisis sistem pelaksanaan kelas ibu hamil di Puskesmas Malalak dan Biaro Kabupaten Agam. Ini adalah suatu penelitian deskriptif kualitatif dengan melakukan wawancara terhadapa informan penelitian yang terdiri dari kepala dan kasie KIA (Kesehatan ibu dan Anak) dinas kesehatan kabupaten, kepala, fasilitator dan kader puskesmas, serta ibu hamil peserta kelas ibu hamil. Analisis input pelaksanaan kelas ibu hamil yaitu masih kurangnya pemahaman dari kebijakan yang sudah ada, tenaga yang belum cukup dan belum dilatih, sarana dan prasarana yang belum memadai. Analisis proses menunjukkan belum ada sosialisasi dengan stakeholder terkait, tahapan persiapan yang kurang matang karena kurangnya pertimbangan latar belakang budaya di Malalak, sehingga ditemukan berbagai kendala dalam hal pelaksanaan. Analisis output yaitu belum ada monitoring dan evaluasi khusus yang dilakukan oleh dinas kesehatan Kabupaten Agam dan kepala puskesmas Malalak. Secara keseluruhan kurangnya peran bidan dalam menjalankan tugas dan fungsinya sebagai pelaksana pelayanan kebidanan di komunitas dan belum adanya kolaborasi antar profesi dalam menjalankan program $\mathrm{KIH}$. Sistem pelaksanaan kelas ibu hamil belum sesuai dengan pedoman pelaksanaan kelas ibu hamil. Perlu berbagai upaya yang dilakukan untuk mengoptimalkan dan mengembangkan pelaksanaan kelas ibu hamil.
\end{abstract}

Kata kunci: puskesmas, analisis sistem, kelas ibu hamil

\begin{abstract}
Antenatal class is a learning tool for pregnant women to obtain sufficient knowledge to prevent complication, increase coverage of antenatal visits and having child delivery at the health care practitioner. The objective of this study was to analyze the system of antenatal class in Malalak and Biaro in Agam District. This is a descriptive qualitative study conducted interviews Informants as chief and section chief of maternal and child health department, head clinics, facilitator, cadre clinics and pregnant women who attend antenatal class. Analysis of input were lack of understanding of policy about antenatal class, lack of human resources and have not been trained for antenatal class, and inadequate infrastructure. Analysis of process showed the absence of socialization with relevant stakeholders, poor preparation which cause by lack of concern in culture in Malalak that make many barriers in implementation. Analysis of output showed the absence of specific monitoring and evaluation by ministry of health department and head of Malalak HC. In the whole system there is a lack of active role of midwife as a midwivery care practitioner in community in performing her duties and functions and there is none of interprofessional collaboration in implementation of this program. System of antenatal classes is not accordance with the guideline of antenatal class. Necessary effort to optimize and expand antenatal class implementation.
\end{abstract}

Keywords: health care, system analysis, antenatal class

Affiliasi penulis : 1. Program Studi Magister Kebidanan FK UNAND (Fakultas Kedokteran Universitas Andalas Padang), 2. Bagian
Kebidanan FK UNAND/RSUP Dr. M Djamil Padang, 3. Program Studi Magister Kesehatan Masyarakat Universitas Andalas Padang 
Korespondensi : Ayu Nurdiyan, Jl. Birugo Puhun No. 1F, Bukittinggi, E-mail: ayu.pieter@gmail.com, Telp: 082388645156

\section{PENDAHULUAN}

Upaya untuk memperbaiki kesehatan ibu, bayi baru lahir dan anak telah menjadi prioritas utama dari pemerintah sebelum Millenium Development Goal's (MDG's) 2015 ditetapkan. Angka kematian ibu (AKI) dan Angka Kematian Bayi (AKB) merupakan salah satu indikator utama derajat kesehatan suatu negara. AKI dan AKB juga mengindikasikan kemampuan dan kualitas pelayanan kesehatan, kapasitas pelayanan kesehatan, kualitas pendidikan dan pengetahuan masyarakat, kualitas kesehatan lingkungan, sosial budaya serta hambatan dalam memperoleh akses terhadap pelayanan kesehatan. ${ }^{1}$

Angka Kematian lbu (AKI) di berbagai wilayah di Indonesia cukup beragam. Ada kabupaten yang sudah bagus tetapi ada yang jauh dari harapan, tergantung kondisi geografis, tingkat kemiskinan, daerah konflik dan sebagainya. Untuk kematian ibu di Indonesia, Sumbar menempati posisi 14 yaitu 197/100 ribu kelahiran. Cakupan K1, K4 dan persalinan oleh tenaga kesehatan di provinsi Sumatera Barat juga belum mencapai target MDG's 2015 Sehingga dalam rekomendasi di Rakernas 2014 dinyatakan bahwa untuk provinsi Sumbar tahun 2012 disarankan untuk mengaktifkan kembali desa siaga melalui kelas ibu hamil. $^{2}$

$\mathrm{KIH}$ (Kelas Ibu Hamil) merupakan salah satu program kesehatan yang diharapkan turut berperan dalam menurunkan angka kesakitan dan kematian akibat kehamilan, persalinan dan nifas. $\mathrm{KIH}$ merupakan sarana belajar bersama yang perlu diikuti oleh ibu hamil agar memperoleh pengetahuan yang cukup sehingga dapat mencegah komplikasi dan meningkatkan cakupan $\mathrm{K} 1, \mathrm{~K} 4$ serta melakukan persalinan pada tenaga kesehatan. ${ }^{3}$

Di Kabupaten Agam, KIH sudah dilaksanakan di seluruh Puskesmas sejak tahun 2009 dan sudah ada Puskesmas Biaro yang dijadikan Puskesmas Percontohan Kelas lbu Hamil, dimana sudah tersedia ruangan khusus yang dipergunakan untuk kelas ibu hamil dan bahan serta alat lain yang dilengkapi didalamnya tetapi untuk beberapa puskesmas lain dalam hal sarana prasarana, dan pelaksanaan masih kurang optimal serta mengalami hambatan.
Puskesmas Malalak merupakan Puskesmas yang terletak di Kecamatan Malalak, selain itu juga terdapat 2 Polindes, 2 Poskesri, dan 22 Posyandu di Kecamatan Malalak sendiri. Namun dalam pelaksanaan kelas ibu hamil Puskesmas Malalak masih mengalami hambatan dalam hal kemauan ibu hamil untuk mengikuti kelas ibu hamil, bahkan untuk beberapa program lainnya secara keseluruhan di wilayah kerja Puskesmas Malalak masih mengalami kekurangan dalam hal pencapaian target program kesehatan.

Gambaran umum untuk pelaksanaan kelas ibu hamil di Kabupaten Agam dalam hal pelaksanaan kelas ibu hamil dari survey awal yang dilakukan salah satunya yaitu pelatihan fasilitator tidak dilakukan training on the job melainkan hanya sosialisasi oleh Dinas Kabupaten Agam kepada tenaga kesehatan seperti Dokter umum, Bidan, dan Perawat dan untuk evaluasi pelaksanaan program yang dilaksanakan khusus tentang $\mathrm{KIH}$ belum pernah dilakukan. Penelitian ini bertujuan untuk menganalisis sistem pelaksanaan $\mathrm{KIH}$ di Puskesmas Malalak dan Puskesmas Biaro Kabupaten Agam tahun 2014.

\section{METODE}

Penelitian ini merupakan penelitian deskriptif kualitatif. Metode penelitian kualitatif adalah suatu jenis penelitian yang temuannya tidak diperoleh melalui prosedur statistika atau bentuk hitungan lainnya. Penelitian ini dilakukan di Puskesmas Malalak dan Puskesmas Biaro Kabupaten Agam. Waktu penelitian pada bulan Februari sampai Mei 2014.

Pada penelitian kualitatif, peneliti melakukan wawancara dengan orang-orang yang dipandang tahu berhubungan dengan tujuan penelitian tersebut yang selanjutnya disebut dengan informan penelitian. Penentuan sumber data pada orang yang diwawancarai / informan penelitian dilakukan secara purposive, yaitu dipilih dengan pertimbangan tujuan tertentu. ${ }^{4}$ Pada penelitian ini informan berjumlah 25 orang yang terdiri dari Kepala dan Kasie. KIA dinas kesehatan, kepala puskesmas, fasilitator, kader dan ibu hamil yang menjadi peserta $\mathrm{KIH}$.

Dalam penelitian kualitatif, yang menjadi instrumen penelitian adalah peneliti sendiri, selanjutnya ditambah dengan panduan wawancara 
yang sudah disusun secara tertulis sesuai dengan masalah, kemudian digunakan sebagai sarana untuk mendapatkan informasi yang selanjutnya akan menjadi data primer. Instrumen lainnya yaitu berupa lembaran observasi yang digunakan untuk membantu peneliti memperoleh data sekunder dari dokumendokumen yang dimiliki Dinas Kesehatan Kabupaten Agam, Puskesmas Malalak dan Puskesmas Biaro.,

Teknik pengumpulan data dilakukan dengan 4 cara yaitu wawancara mendalam, diskusi kelompok terarah, observasi, dan telaah dokumen. Data yang didapat, dilakukan validasi dengan cara triangulasi. Selanjutnya data diolah dengan melalui beberapa tahap: transkrip data, reduksi data, display data, penarikan kesimpulan dan verifikasi. ${ }^{7}$

\section{HASIL DAN PEMBAHASAN}

Analisis proses diketahui bahwa belum pernah dilakukannya pelatihan fasilitator kelas ibu hamil sebelumnya karena terbatasnya alokasi dana untuk pengembangan $\mathrm{KIH}$ dan semua pihak berpatokan hanya dari dana BOK (Bantuan Operasional Kesehatan) yang tersedia dan kurangnya kemampuan setiap bidan sebagai tenaga kesehatan yang berwenang di wilayah kerjanya di puskesmas untuk menjadi fasilitator setiap diadakannya $\mathrm{KIH}$ serta kurangnya keaktifan pengelola $\mathrm{KIH}$ dari kabupaten dan puskesmas untuk melibatkan seluruh stakeholder terkait seperti tokoh masyarakat, tokoh agama, PKK (Pembinaan Kesejahteraan Keluarga), bundo kanduang dan kader. Sehingga diperlukan pelatihan fasilitator yang terprogram dan terjadwal untuk meningkatkan kemampuan petugas dalam memfasilitasi $\mathrm{KIH}$ dan memberdayakan bidan di desa untuk dapat memfasilitasi $\mathrm{KIH}$ di wilayah kerja mereka sehingga alasan adanya hambatan dalam masalah dana bukan menjadi alasan lagi. Selain itu, diperlukan kepercayaan diri dan pemahaman bidan dalam memimpin wilayah kerjanya dalam pelayanan kebidanan komunitas.

Hasil wawancara sehubungan dengan kebijakan dan tujuan umum dibuatnya program $\mathrm{KIH}$, terlihat bahwa visi yang dipegang oleh pembuat kebijakan dalam hal ini tentang tujuan kelas ibu hamil ini sudah sangat jelas bentuk komitmen dari Dinas Kesehatan Kabupaten Agam sendiri dengan mendukung diadakannya $\mathrm{KIH}$. Hasil telaah dokumen tentang pelaksanaan KIH di Dinas Kesehatan Kabupaten juga terlihat bahwa pada April 2014 sudah ada laporan rekap $\mathrm{KIH}$ dari seluruh puskesmas di kabupaten Agam.

Bentuk kebijakan yang diberikan oleh dinas kesehatan kabupaten adalah sudah disiapkannya dana untuk $\mathrm{KIH}$ ini dan adanya keharusan bagi seluruh puskesmas untuk melaksanakan kelas ibu hamil dan adanya fasilitator yang memfasilitasi kegiatan $\mathrm{KIH}$. Hal ini juga didukung oleh penjelasan dari kepala Puskesmas Biaro.

Sedangkan untuk dikeluarkannya surat keputusan dari dinas kesehatan sendiri sampai saat ini belum dilakukan karena berdasarkan wawancara dengan Kepala Dinas Kesehatan, adanya perencanaan yang diakomodasi dalam perencanaan pemanfaatan dana BOK dan POA (Plan of Action) setiap puskesmas seharusnya sudah menjadi pedoman dan rekomendasi bagi setiap puskesmas untuk menjalankan program tersebut

Pada tahun 2012, Izzah juga menyebutkan tentang pelaksanaan $\mathrm{KIH}$ di Kabupaten Bulukumba Sulawesi Selatan, di Kabupaten ini kebijakan kelas ibu hamil juga muncul berupa rekomendasi dan dukungan dari Dinas Kesehatan Kabupaten dengan tujuan meningkatkan pengetahuan ibu hamil dan pemantauan kesehatan ibu hamil secara berkala. ${ }^{8}$ Tidak berbeda juga dengan Inggris, rekomendasi untuk diadakannya $\mathrm{KIH}$ juga dibuat oleh Department of Health di Inggris melalui National Service Framework for Children, Young People and Maternity Services yang memperbolehkan diselenggarakannya $\mathrm{KIH}$ oleh institusi kesehatan maupun lembaga swadaya masyarakat, tidak hanya berupa rekomendasi, NHS (National Health Services) dalam hal ini juga memberikan dukungan dalam hal anggaran dalam penyelenggaraan $\mathrm{KIH}$ tersebut. ${ }^{9}$

Kewenangan bidan dalam menjalankan program pemerintah berwenang melakukan pelayanan kesehatan yang salah satunya yaitu asuhan antenatal yang terintegrasi, melakukan pembinaan peran serta masyarakat, melaksanakan pelayanan kebidanan komunitas, dan melakukan pelayanan kesehatan lain yang merupakan program pemerintah, hal ini tercantum pada Peraturan menteri kesehatan 
(Permenkes) nomor 1464 tahun 2010 pasal 13 dan pada pasal 18 juga ditambahkan bahwa dalam melaksanakan praktiknya bidan berkewajiban untuk membentuk program pemerintah dalam meningkatkan derajat status kesehatan masyarakat. ${ }^{10}$ Jadi, pada prinsipnya jika merujuk pada permenkes tahun 2010 sendiri, tugas dan kewenangan bidan dalam menjalankan segala jenis program pemerintah termasuk $\mathrm{KIH}$ sudah diatur dalam peraturan menteri kesehatan ini.

Penyebab dari masalah ini mungkin juga karena masih kurangnya pemahaman bidan terhadap permenkes yang sudah ada, dan kurangnya sosialisasi oleh organisasi profesi sehubungan dengan permenkes ini. ICM (International Confederation of Midwives) dalam laporannya di Kongres tahun 2014 mengingatkan kembali tentang perlunya penguatan dan penyegaran kembali oleh organisasi profesi segala hal yang berhubungan dengan kebijakan dan program pemerintah yang bertujuan untuk menurunkan angka kematian dan kesakitan ibu. ${ }^{11}$

Di Puskesmas Malalak terdapat hambatan kurangnya $\mathrm{KIH}$ dalam pelaksanaan $\mathrm{KIH}$ karena adanya alasan bahwa tempat pelaksanaan $\mathrm{KIH}$ terlalu jauh dari tempat tinggal. Hal serupa juga terjadi di Inggris, setelah adanya rekomendasi dari departemen kesehatan untuk melaksanakan kelas ibu hamil pada tahun 2004, pada tahun 2007 di beberapa wilayah di Inggris penyelenggaran $\mathrm{KIH}$ tidak dilakukan. Di Inggris ini, data tentang dimana lokasi ibu hamil sulit didapatkan karena ibu hamil tersebar di beberapa tempat sehingga mereka menggunakan pendekatan mikrosimulasi untuk memperkirakan area dimana ibu hamil berada sehingga pembuat kebijakan dapat memperkirakan lokasi untuk kelas ibu hamil, kehadiran ibu hamil dalam kelas ibu hamil dapat ditingkatkan. ${ }^{12}$ Selain itu perlu dipertimbangkannya latar belakang budaya dan lingkungan dari wilayah ini, karena pada wilayah kerja Puskesmas Malalak, bukan hanya program $\mathrm{KIH}$ saja yang mengalami hambatan dalam partisipasi ibu hamil tetapi hampir seluruh program mengalami hambatan yang serupa.

Fasilitator kelas ibu hamil adalah bidan atau petugas kesehatan yang telah mendapat pelatihan fasilitator kelas ibu hamil dan setelah itu diperbolehkan melaksanakan fasilitasi kelas ibu hamil. ${ }^{3}$ Dari sisi ketenagaan bagi pelaksanaan kelas ibu hamil, kepala dinas kesehatan kabupaten menjelaskan bahwa untuk Kabupaten Agam sendiri, dari tenaga yang ada saat ini sudah cukup tetapi yang kurang adalah kemampuan tenaga yang sudah ada ini dalam memfasilitasi kelas ibu hamil yang masih kurang. Hal ini yang menjadi salah satu masalah dalam hal ketenagaan $\mathrm{KIH}$ di Kabupaten Agam, solusinya memang diperlukan pelatihan tetapi belum dapat dilakukan karena berkaitan dengan masalah anggaran yang belum ada. Pernyataan dari kepala dinas ini juga disebutkan oleh Kasie. KIA, kepala puskesmas dan Bidan fasilitator di puskesmas. Kepala puskesmas Biaro menyatakan bahwa solusi di Biaro adalah $\mathrm{KIH}$ tetap dilakukan dengan melihat buku pedoman yang sudah ada. Kepala puskesmas di Biaro dan Malalak juga menambahkan bahwa untuk setiap kelas ibu hamil yang dilakukan masih harus difasilitasi oleh bidan pengelola KIA di puskesmas.

Dalam pelaksanaan kelas ibu hamil, bukan hanya fasilitator yang berperan penting melainkan juga Dinas Kesehatan dalam hal dukungan, Kepala Puskesmas dalam hal monitoring dan keaktifan kader yang terlibat dalam pelaksanaan $\mathrm{KIH}$ ini serta dukungan penuh dari tokoh masyarakat setempat. Pada tahun 2012, Izzah menyebutkan bahwa di Kabupaten Bulukumba, KIH dilaksanakan di tingkat desa dengan mengoptimalkan fungsi PKK, para perangkat desa, dan bidan desa. Pengelolaan $\mathrm{KIH}$ sendiri dibantu oleh peranan Kelompok Peminat Kesehatan lbu dan Anak (KPKIA) yang mempersiapkan pelaksanaan KIH ini. Di Kabupaten Bulukumba ini, Kabid Kesmas juga memainkan peran dalam mempertemukan berbagai pihak untuk mendukung program ini dan memobilisasi dukungan anggaran dari pemerintah; Kepala Desa mendukung dengan alokasi anggaran desa dan membantu mengkoordinasikan keterlibatan warga dalam penyedia sarana transportasi; kader yang aktif dalam setiap kegiatan yang dilakukan bidan desa dan JICA sebagai lembaga donor. ${ }^{8}$

Terselenggaranya kelas ibu hamil yang baik di Kabupaten Bulukumba ini dapat disimpulkan berjalan lancar karena adanya partisipasi stakeholder yang mendukung penuh pelaksanaan $\mathrm{KIH}$, adanya peran kelompok pendukung dari tim penggerak PKK, KPKIA, pemerintah desa, dan bidan. ${ }^{8}$ Hasil observasi yang dilakukan di Biaro, partisipasi berbagai pihak 
dalam penyelenggaraan $\mathrm{KIH}$ di wilayah ini sudah baik, tetapi untuk Malalak, kesadaran pemerintah nagari, kader, dan ibu hamil nya sendiri yang memang belum ada untuk mendukung dan mengikuti $\mathrm{KIH}$ ini. Di kabupaten Bulukumba, terselenggaranya $\mathrm{KIH}$ adalah praktik pengembangan kesehatan berbasis masyarakat, dimana masyarakat tidak hanya menjadi obyek program melainkan menjadi pelaksana, penggerak, bahkan penyandang dana. Pendekatan persiapan $\mathrm{KIH}$ seperti ini yang mungkin dapat dilakukan untuk terselenggaranya $\mathrm{KIH}$ dan meningkatnya kesadaran masyarakat tentang pentingnya kelas ibu hamil ditambah lagi dengan pendekatan based practice, dimana seperti yang dijelaskan sebelumnya bahwa perlu adanya pertimbangan latar belakang budaya dan lingkungan setempat.

Hasil observasi dan telaah dokumen yang dilakukan terlihat bahwa anggaran untuk puskesmas Biaro setiap kali melakukan pertemuan $\mathrm{KIH}$ lebih kecil dibandingkan dengan anggaran puskesmas Malalak. Namun, puskesmas Biaro sendiri dapat melakukan 19 kali pertemuan $\mathrm{KIH}$ dibandingkan dengan Malalak yang hanya 4 kali pertemuan. Jika melihat anggaran di puskesmas Biaro sendiri, anggaran untuk snack, narasumber, dan ATK (Alat Tulis Kantor) jauh lebih sedikit dibandingkan dengan anggaran di Malalak. Menimbang permasalahan umum dari pelaksanaan $\mathrm{KIH}$ di Puskesmas Malalak sendiri dijelaskan oleh pengelola $\mathrm{KIH}$ bahwa hambatan dalam pelaksanaan adalah kurangnya partisipasi ibu hamil dalam hal kehadiran dan kesadaran untuk mengikuti kelas ibu hamil karena persebaran wilayah yang sangat luas dan kurangnya transportasi. Hal ini dapat menjadi bahan pertimbangan untuk menekan anggaran lain untuk menambah anggaran untuk penyediaan transportasi bagi ibu hamil.

Sosialisasi $\mathrm{KIH}$ pada tokoh agama, tokoh masyarakat, dan stakeholder sebelum $\mathrm{KIH}$ dilaksanakan sangat penting. Masalah yang ada yaitu belum dilakukannya sosialisasi terhadap stakeholder terkait, padahal sosialisasi ini sangat diperlukan untuk meningkatkan pemahaman dan dukungan kongkrit dalam pelaksanaan kelas ibu hamil, sosialisasi terhadap suami juga perlu dilakukan agar suami juga dapat berpartisipasi dalam $\mathrm{KIH}$ dan peningkatan kemampuan bidan dalam hal advokasi setiap program pemerintah. $^{3}$

Persiapan untuk dilaksanakannya $\mathrm{KIH}$ juga seringkali menemui hambatan, karena belum dilakukannya semua tahapan yang terdapat dalam pedoman yang sudah ada. Sehingga diharapkan dapat melakukan tahapan persiapan $\mathrm{KIH}$ yang lebih optimal sesuai dengan buku pedoman yang sudah ada sehingga kendala dalam pelaksanaan dapat dikurangi, dibentuknya tim pelaksana kegiatan kelas ibu hamil, dipertimbangkannya pendekatan mikrosimulasi berupa pemetaan kelas ibu hamil sebelum ditentukannya lokasi pertemuan $\mathrm{KIH}$ sehingga kehadiran ibu hamil dapat ditingkatkan dengan diminimalisasinya hambatan lokasi $\mathrm{KIH}$ yang terlalu jauh di wilayah Malalak dan yang paling penting adalah perlu adanya peningkatan profesionalisme dari masing-masing individu tenaga kesehatan yang terlibat dalam setiap kolaborasi interprofesi. ${ }^{12,13}$

The State of Worlds Midwifery pada tahun 2011 menyebutkan bahwa seorang bidan harus dapat memungkinkan adanya kebijakan dan lingkungan untuk memaksimalkan peran bidan sebagai tenaga kesehatan di kebidanan komunitas. Pada prinsipnya seorang bidan harus kreatif dalam menciptakan kebijakan yang dapat membantu dalam meningkatkan pelayanan kebidanan bagi ibu dan anak sehingga adanya kekurangan dalam hal ketenagaan dapat diatasi. The State of Worlds Midwifery tahun 2011 menyebutkan bahwa bidan harus dapat bekerja dalam tim dan berkolaborasi dengan profesi kesehatan lain, dalam hal ini bidan di desa harusnya dapat berkolaborasi dengan tenaga kesehatan di puskesmas dalam menjalankan setiap program kesehatan khususnya kelas ibu hamil. ${ }^{14}$

Dalam ICM Triennal Congress di Prague tahun 2014 ini juga dilaporkan bahwa international confederation of midwives (ICM) menyebutkan bahwa seorang bidan harus dapat membentuk kebijakan global dimana tujuannya adalah untuk meningkatkan kesadaran bidan dan memperluas pengaruh bidan yang bertujuan untuk mengadvokasi adanya perubahan kebijakan sehubungan dengan pelayanan kesehatan ibu, anak dan kesehatan reproduksi. Selain itu dalam kongres ini juga menyebutkan bahwa perlu adanya penguatan kebidanan melalui adanya 
kolaborasi dengan teman sejawat yang bertujuan untuk memperkuat kerja tim untuk meningkatkan derajat status kesehatan masyarakat dan berbagi visi untuk meningkatkan promosi kesehatan bagi ibu dan keluarga dalam memberikan dukungannya di setiap program kesehatan. ${ }^{11}$

Peran bidan dalam pelayanan kebidanan komunitas kembali menjadi perhatian dalam hal ini, seorang bidan bukan hanya berperan dalam pelayanan kesehatan ibu dan anak saja melainkan juga dalam advokasi untuk berjalannya sebuah program kesehatan dengan baik. Seorang bidan harus mampu mengembangkan dan meningkatkan praktik mereka, berpikir inovatif sebagai seorang pemimpin, berkontribusi dalam sistem pelayanan kebidanan. Seorang bidan merupakan professional yang mandiri tetapi tetap memerlukan kolaborasi dengan tenaga professional kesehatan lainnya. ${ }^{15}$

Pada tahun 2012, Izzah menjelaskan sehubungan dengan persiapan pelaksanaan $\mathrm{KIH}$ menjelaskan bahwa, di Bulukumba persiapan dilakukan oleh KPKIA yang menetapkan ketua kelas dan anggota kelas, kemudian masing-masing kelas membuat kesepakatan tempat dan waktu untuk penyelenggaraan kelas. Awalnya ibu hamil didata untuk dimasukkan sebagai peserta kelas, kemudian dibuatlah kelas rutin bagi mereka. Dengan cara seperti ini, ibu hamil sendiri yang dilibatkan secara aktif dalam menetapkan jadwal kelas ibu hamil akan dilaksanakan. Cara ini sesuai juga dengan buku pedoman kelas ibu hamil yang telah dipegang oleh masing-masing puskesmas sebagai penuntun pelaksanaan kelas ibu hamil. ${ }^{3,8}$

Tahapan terakhir yang paling penting dalam persiapan pelaksanaan kelas ibu hamil adalah dibentuknya tim pelaksana kelas ibu hamil yang diambil dari berbagai profesi kesehatan yang ada di puskesmas masing-masing. Adanya kerjasama interprofesi yang baik dalam kebidanan komunitas terbukti dapat memperkuat sistem kesehatan dan akhirnya akan meningkatkan derajat dan hasil kesehatan. WHO dalam rekomendasinya tentang pendidikan interprofesi dan kolaborasi interprofesi dalam praktik menjelaskan tiga kunci penting dalam melaksanakan kolaborasi interprofesi dalam praktik yaitu adanya dukungan institusi, tanggap budaya dan adanya lingkungan yang mendukung. ${ }^{15}$
Dalam hal pelaksanaan kelas ibu hamil, hasil observasi, wawancara mendalam, diskusi kelompok terarah, dan telaah dokumen membuktikan kesadaran ibu hamil yang lebih tinggi di wilayah kerja Biaro dibandingkan Malalak. Proses pertemuan kelas ibu hamil, KIH yang dilakukan oleh Puskesmas Biaro lebih sedikit menemui hambatan, hal ini berhubungan dengan adanya latar belakang budaya dan lingkungan dari masyarakat Malalak yang membuat tenaga kesehatan sulit untuk melakukan advokasi. Penulis menyadari bahwa setiap program kesehatan yang dilaksanakan di setiap wilayah kerja masing-masing puskesmas, sangat penting untuk mempertimbangkan latar belakang budaya yang ada di wilayah setempat sehingga pertimbangan yang dilakukan, tim yang terlibat dalam pelaksanaan program tersebut dapat memaksimalkan peran mereka dalam sistem pelaksanaan program tersebut.

Monitoring dilakukan dalam rangka melihat perkembangan dan pencapaian serta masalah dalam pelaksanaan kelas ibu hamil, monitoring dilakukan secara berkala dan berjenjang mulai dari tingkat Desa, Kecamatan, Kabupaten / Kota dan Provinsi. Evaluasi dilakukan untuk melihat keluaran dan dampak baik positif maupun negatif pelaksanaan kelas ibu hamil berdasarkan indikator, dilakukan oleh pelaksana (bidan/koordinator bidan) dilakukan setiap selesai pertemuan. Dinas Kesehatan Kabupaten/Kota serta Dinas Kesehatan Provinsi. Seluruh rangakaian hasil proses pelaksanaan kegiatan kelas ibu hamil dibuatkan laporan. Pelaporan disusun pada setiap selesai melaksanakan kelas ibu hamil. ${ }^{3}$

Sehubungan dengan monitoring pelaksanaan kelas ibu hamil dijelaskan oleh Kepala Dinas Kesehatan dan Kasie KIA bahwa monitoring hanya dilakukan setiap rapat evaluasi bulanan dengan kepala puskesmas. Di puskesmas Malalak sendiri monitoring dilakukan Kepala Puskesmas hanya dari laporan bidan yang melakukan $\mathrm{KIH}$.

Pelaporan juga dipaparkan oleh beberapa informan untuk setiap bulan puskesmas memberikan laporan ke dinas tentang pelaksanaan semua program termasuk kelas ibu hamil. Sedangkan untuk evaluasi dari dinas kesehatan kabupaten sendiri dinyatakan oleh informan bahwa belum ada evaluasi khusus untuk pelaksanaan $\mathrm{KIH}$ tetapi evaluasi hanya 
dilakukan melaui pertemuan bulanan bidan pengelola KIA dengan dinas kesehatan di kabupaten.

Hasil analisis ouput yaitu belum pernah dilakukan monitoring dan evaluasi khusus $\mathrm{KIH}$ dari Dinas Kesehatan Kabupaten setempat. Kepala puskesmas Malalak sendiri juga tidak pernah terlibat atau melakukan monitoring langsung dalam pelaksanaan $\mathrm{KIH}$. Sehingga perlu diingat kembali untuk semua pihak yang menjadi koordinator dalam pelaksanaan kelas ibu hamil untuk dapat menjalankan perannya dalam melakukan monitoring dan evaluasi langsung dalam $\mathrm{KIH}$ dan memberikan peran dan aksi aktif demi terlaksananya $\mathrm{KIH}$ dengan baik.

Puskesmas Biaro melakukan evaluasi sendiri terhadap pelaksanaan $\mathrm{KIH}$ tahun lalu dan mencari solusinya bagi pelaksanaan $\mathrm{KIH}$ tahun ini yaitu dengan melaksanakan tujuh $\mathrm{KIH}$ saja agar pelaksanaan lebih optimal. Evaluasi yang dilakukan oleh puskesmas Biaro ini dapat menjadi bahan pertimbangan untuk perbaikan di puskesmas Malalak, karena kepala puskesmas melihat latar belakang budaya dan lingkungan dari wilayah Biaro dan menyesuaikan dengan program pemerintah yang ada.

Ada beberapa rekomendasi yang disampaikan oleh beberapa informan ibu hamil yaitu: diadakan studi banding antar $\mathrm{KIH}$, narasumber bukan bidan saja dan materi yang diberikan lebih fokus terhadap kendala yang ditemui ibu.

Pada tahun 2011, Nolan menjelaskan bahwa kelas ibu hamil sukses dalam menyediakan sistem dukungan bagi ibu hamil, ibu hamil menemukan persahabatan yang mereka dapatkan dapat membantu mereka dalam membentuk percaya diri dan kompetensi sebagai calon ibu dan dapat menjadi kontribusi yang besar bagi periode pascasalin. Penelitian Nolan ini dapat menjadi sebuah contoh bagaimana kelas ibu hamil tidak hanya menjadi tempat berbagi antara fasilitator dan ibu hamil saja tetapi juga antara sesama peserta. ${ }^{16}$ NCT (National Childbirth Course), pada tahun 2010 juga menjelaskan bahwa kelas ibu hamil dapat menjadi lingkungan yang nyaman untuk mendiskusikan harapan, dan ketakutan, respon positif dari sesama peserta dapat membantu mereka untuk meningkatkan rasa nyaman dan pengalaman. Dukungan sosial yang berkembang selama kelas ibu hamil dapat meningkatkan kesejahteraan ibu. Bahkan dari rekomendasi yang diberikan oleh kader dalam penelitian ini, dapat menjadi tempat berbagi antara sesama peserta kelas ibu hamil yang berbeda. ${ }^{9}$

Pada tahun 2008, Svensson dkk, menjelaskan bahwa dari responden dalam penelitian tersebut mereka menginginkan adanya "serangkaian kuliah" dengan "pembicara tamu yang merupakan seorang yang ahli di bidangnya". ${ }^{17}$ Peserta $\mathrm{KIH}$ ini juga merekomendasikan adanya topik-topik yang terjadwal sebelum mereka mengikuti $\mathrm{KIH}$ dan mereka dapat memilih topik kuliah mana yang akan mereka ikuti. Topik tersebut misalnya pertumbuhan dan perkembangan janin, intervensi medis selama persalinan, dan lain-lain. Ahlden dkk, juga menjelaskan bahwa adanya kerjasama dalam pendidikan antenatal sangat penting dan kolaborasi merupakan salah satu cara untuk memenuhi segala kebutuhan informasi ibu hamil. Rekomendasi dari kader ini juga menjadi rekomendasi oleh bidan fasilitator di Malalak dimana diharapkan dibentuk tim pelaksana kelas ibu hamil sehingga setiap tenaga kesehatan yang ahli di bidangnya dapat menjadi narasumber dalam pertemuan $\mathrm{KIH}^{18}$

Kepala puskesmas Biaro mengharapkan agar diadakannya pelatihan bagi fasilitator $\mathrm{KIH}$ agar mempunyai konsep dan persepsi yang sama sebelum memfasilitasi $\mathrm{KIH}$ dan untuk pengembangan $\mathrm{KIH}$ agar dalam pelaksanaannya $\mathrm{KIH}$ mengikutsertakan suami agar suami juga mengetahui perannya.

Shia dan Alabi pada tahun 2013 juga menjelaskan bahwa dari 49 orang suami yang menjadi responden dalam penelitian tersebut, semuanya memilih mengikuti kelas yang sama dengan istri mereka, 23 orang suami memilih mengikuti kelas untuk suami saja. Hal yang menjadi perhatian disini adalah walaupun mereka memilih mengikuti kelas yang sama dengan pasangannya maupun tidak, tujuan mereka menghadiri kelas tersebut adalah agar mereka lebih siap dalam hal pengalaman dan sikap dalam menghadapi persalinan dan kelahiran bayinya, dan terlihat secara aktif dalam pendidikan antenatal. ${ }^{19}$ Fletcher dkk pada tahun 2014 juga menambahkan bahwa, dari 212 suami yang mengikuti kelas ibu hamil, sebagian besar merasa mereka lebih siap untuk menjadi calon ayah untuk kelahiran bayinya dan perannya sebagai pendamping ibu. ${ }^{20}$ Jadi dengan adanya partisipasi suami dalam $\mathrm{KIH}$ di masa yang 
akan datang di Kabupaten Agam diharapkan dapat meningkatkan sistem dukungan bagi ibu dan juga peran suami dalam kesehatan ibu dan bayinya nantinya.

\section{KESIMPULAN}

Sistem pelaksanaan kelas ibu hamil belum sesuai dengan pedoman pelaksanaan kelas ibu hamil yang dikeluarkan oleh Kemenkes RI. Pelaksanaan program kesehatan khususnya kelas ibu hamil $(\mathrm{KIH})$ memerlukan pendekatan based practice, dimana adanya pertimbangan latar belakang budaya dan lingkungan setempat sehingga tim yang terlibat dalam pelaksanaan program tersebut dapat memaksimalkan peran mereka dalam sistem pelaksanaan program tersebut. Perlu berbagai upaya yang dilakukan untuk mengoptimalkan dan mengembangkan pelaksanaan kelas ibu hamil.

\section{DAFTAR PUSTAKA}

1. World Health Organization. System thinking for strengthening health policy. France: WHO Library Cataloguing-in-Publication Data. 2009 (diunduh 2 Januari 2014). Tersedia dari: URL: HYPERLINK http://whqlibdoc.who.int/publications/2009/9789241 563895 eng.pdf

2. Pusat Data dan Informasi Kemenkes RI. Ringkasan eksekutif: data dan Informasi kesehatan provinsi Sumbar. 2012 (diunduh 6 Oktober 2013). Tersedia dari: URL: HYPERLINK https://id.scribd. com/doc/2079775260?width $=600$

3. Kemenkes RI. Pedoman pelaksanaan kelas ibu hamil. Jakarta: Dirjen Bina Kesehatan Masyarakat Indonesia; 2012.

4. Sugiyono. Memahami penelitian kualitatif. Yogyakatta: CV Alfabeta; 2009.

5. Sarwono J. Metode penelitian kuantitatif dan kualitatif. Yogyakarta: Graha IImu; 2009.

6. Saryono, Anggraeni, Dwi M. Metode penelitian kualitatif dalam bidang kesehatan. Yogyakarta: Nuha Media; 2010.

7. Moleong L. Metodologi penelitian kualitatif. Bandung: PT Remaja Rosdakarya; 2004.

8. Izzah A. Memantau kehamilan melalui kelas ibu hamil di Kabupaten Bulukumba. 2011. (diunduh 14
Juni 2014). Tersedia dari: URL: HYPERLINK http://igi.fisipol.ugm.ac.id

9. NCT Antenatal services. Policy, practice and evidence. London: National Childbirth Trust; 2010.

10. Kemenkes RI. Izin Penyelenggaraan praktik bidan. Peraturan Menteri Kesehatan No. 1464/Menkes/Per/X/2011. 2010.

11. International Confederation of Midwives. Triennial Report 2011 - 2014. (diunduh 29 Agustus 2014). Tersedia dari: URL: HYPERLINK http://www. internationalmidwives.org

12. Tomintz MN, Clarke GP, Rigby JE, Green JM. Optimising the location of antenatal classes. The Elsevier journal. Midwifery. 2011; 29: 33-43.

13. World Health Organization. Framework for action in interprofessional education and collaborative practice. Geneva: WHO Press, World Health Organization. 2010 (diunduh 5 Oktober 2014). Tersedia dari: URL: HYPERLINK http://whqlibdoc.who.int/HQ/2010/WHO HRH HP N 10.3 eng.pdf.

14. UNFPA. Midwifery around the world Part 1. 2011. (diunduh 22 Agustus 2014). Tersedia dari: URL: HYPERLINK http://www.unfpa.org/sowmy/resour ces/docs/main report/en SOWMR Part1.pdf

15. Midwifery 2020 Programme. Midwifery 2020: delivering expectations. Cambridge: Jill Rogers Associates; 2010.

16. Nolan ML, Mason V, Snow S, Messenger W, Catling J, Upton P. Making friends at antenatal classes: A qualitative exploration of friendship across the transition to motherhood. Journal of Perinatal Education. 2012; 21(3):178-84.

17. Svensoon J, Barclay L, Cooke M. Effective antenatal education: strategies recommended by expectant and new parents. Journal of Perinatal Education. 2008: 17(4);33-42.

18. Ahlder I, Ahlehagen S, Dahlgren LO, Josefsson A. Parents expectation about participating in antenatal parenthood education classes. Journal of Perinatal Education. 2012; 21(1):11-6.

19. Shia, N. Alabi, O. An evaluation of male partner's perceptions of antenatal classes in national health service hospital: implications for service Provision in London. 2013: 22(1) 30-7. 
20. Fletcher R, Silberberg S, Galloway D. New father's views of antenatal classes: Satisfaction, benefits, and knowledge of family services. Journal of Perinatal Education.2004;13(3):18-25. 